\title{
МЕЖДИСЦИПЛИНАРНЫЕ ИССЛЕДОВАНИЯ ОТДЕЛА АЭРОЛОГИИ И ТЕПЛОФИЗИКИ
}

\author{
Л.Ю. Левин \\ Горный институт УрО РАН, г. Пермь
}

\begin{abstract}
Аннотация: На сегодняшний день решение многих фундаментальных и прикладных задач в различных областях науки и, в частности, в рудничной аэрологии требует применения большого количества методов и подходов из совершенно разных областей знаний. В этом случае эффективное решение поставленных научно-технических задач невозможно без создания коллабораций между аэрологами и специалистами из других областей знаний. В настоящей статье сделан краткий обзор наиболее интересных исследований, проведенных нами в последние 5 лет, на стыке аэрологии с другими науками - как горными, так и естественными науками, науками о Земле.

Ключевые слова: рудничная аэрология, горная теплофизика, междисциплинарные исследования, соляной аэрозоль, искусственное замораживание грунтов, тепломассоперенос, мониторинг.
\end{abstract}

\section{Введение}

По мнению многих ученых и исследователей в настоящее время считается, что самые важные научные прорывы и открытия совершаются «на стыке наук» [1]. С данным тезисом трудно не согласиться. Более того, опыт выполнения научнотехнических работ сотрудниками отдела аэрологии и теплофизики Горного института УрО РАН свидетельствует о справедливости данного тезиса в более сильной форме: множество научных задач, с которыми приходится сталкиваться, можно решить только с использованием методов и знаний из двух или более областей научного знания.

За последние 5 лет сотрудникам нашего отдела неоднократно приходилось сталкиваться с задачами, для решения которых требовались знания не только аэрологии и горного дела, но также геофизики, геологии, геохимии, механики твердого деформируемого тела и гидрогазодинамики. В этой статье сделан краткий обзор четырех наиболее интересных задач на стыке различных областей знания, решенных сотрудниками нашего отдела аэрологии и теплофизики совместно с коллегами из других научных подразделений и организаций:

1. Динамика соляного аэрозоля в выработках калийных рудников.

2. Нормирование микроклиматических условий для глубоких рудников.

3. Расчет и мониторинг искусственного замораживания грунтов.

4. Деформационный мониторинг надшахтного здания скипового ствола.

\section{Динамика соляного аэрозоля в выработках калийных рудников}

В настоящее время практически на всех калийных рудниках остро стоит вопрос снижения запыленности рабочих мест в подземных горных выработках. Для решения этого вопроса сотрудниками нашего отдела был предложен план комплексных экспериментально-теоретических исследований динамики, состава и свойств гигроскопического аэрозоля калийно-магниевых горных пород в воздушной среде горных выработок для разработки мероприятий и способов по управлению запыленностью рудничной атмосферы горных выработок калийных рудников. Эти исследования позволяют в перспективе минимизировать проблему высокой, многократно превышающей предельно допустимые значения концентрации пылевого аэрозоля, образующегося в технологическом процессе добычи калийно-магниевых руд и негативно воздействующего как на сам технологический процесс, так и на здоровье горнорабочих [2, 3]. 


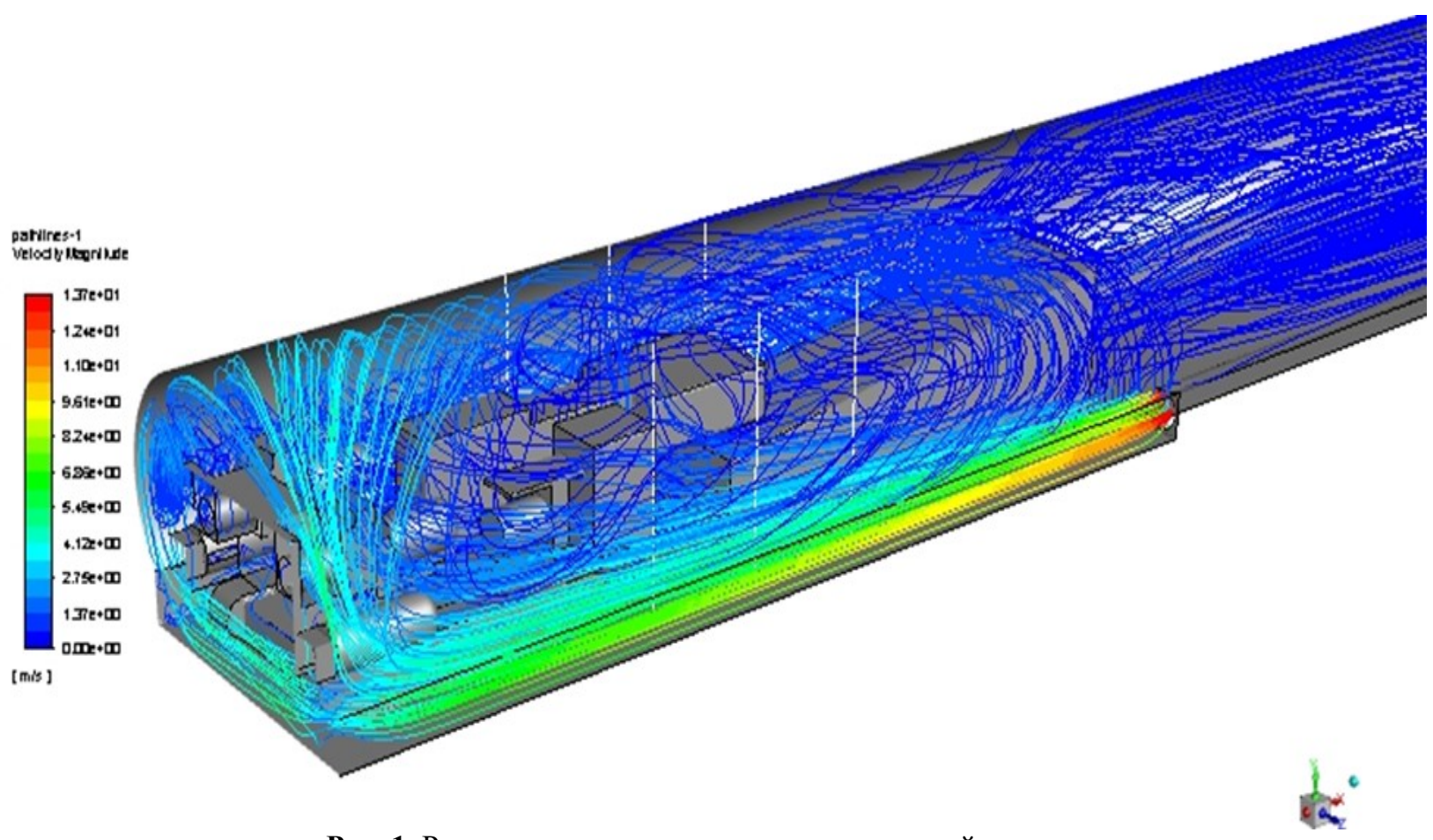

Рис. 1. Рассчитанные линии тока пылевоздушной смеси в тупиковой горной выработке

Для проведения теоретического исследования закономерностей генерации и движения пыли в тупиковом забое горной выработки с работающим комбайном Урал 20Р были привлечены специалисты из лаборатории Вычислительной гидродинамики Института механики сплошных сред УрО РАН, обладающие уникальными компетенциями в проведении численного моделирования тепломассопереноса в жидких и газообразных средах. При этом экспериментальные исследования, а также комплексный анализ данных экспериментов и вычислений проводились в основном сотрудниками нашего отдела, обладающими необходимыми компетенциями в вопросах горного дела. В результате совместных исследований закономерностей накопления и выноса соляного аэрозоля из тупиковой горный выработки (см. рис. 1) при применении различных способов проветривания впервые получен ряд интересных выводов, важных как для рудничной аэрологии, так и для вычислительной гидроаэродинамики. В частости показана существенная роль тепловой конвекции, обусловленной нагревом воздуха в системе обдува двигателей комбайна, в распределении воздушных потоков и концентрации пыли в тупиковой выработке. Обоснована эффективность всасывающего способа проветривания тупиковых выработок с работающим комбайном, получена и параметризована сетевая модель пылераспределения в рудничной атмосфере [3].

\section{Нормирование микроклиматических условий для глубоких рудников}

Еще один важный фактор здоровья горнорабочих - тепловой. На сегодняшний день горнодобывающие предприятия всё чаще вовлекают в отработку новые глубокозалегающие месторождения. С увеличением глубины возрастает температура горных пород, а это приводит к ухудшению микроклиматических условий в подземных горных выработках. Так, например, обстоит дело на калийном руднике Гремячинского ГОКа ООО «ЕвроХим-Волгакалий», где глубина ведения горных работ превышает 1000 метров, а измеренная температура воздуха в некоторых рабочих зонах превышает $+40^{\circ} \mathrm{C}[4]$. 
Согласно действующим «Правилам безопасности при ведении горных работ ...», при температуре воздуха свыше $+26^{\circ} \mathrm{C}$ должно предусматриваться его охлаждение или разрабатываться мероприятия, предусматривающие режим работы персонала с перерывами на отдых в специально оборудованных местах с температурой воздуха не выше $+26^{\circ} \mathrm{C}$. Однако в существующей нормативной литературе не регламентируются конкретные параметры для применения мероприятий: значения для допустимого времени выполнения работ, условия для организации отдыха, не устанавливались предельные значения микроклиматических условий с учетом влажности и скорости воздуха.

По данной причине для обоснования безопасных условий труда по фактору микроклимата для условий рудника потребовалось провести научные исследования, включавшие исследования критериев нормирования микроклиматических условий в горных выработках [5], измерения уровня энергозатрат подземных рабочих и средневзвешенного индекса тепловой нагрузки среды. Данные исследования проводились совместно со специалистами из Федерального научного центра медико-профилактических технологий управления рисками здоровью населения. Специалисты данного учреждения проводили измерения частоты сердечных сокращений, наблюдения за тяжестью и временем выполняемых работ горнорабочими с последующей статистической обработкой данных. Специалисты отдела аэрологии и теплофизики проводили детальные экспериментальные исследования микроклиматических параметров в рудничной атмосфере, разрабатывали математическую модель тепломассопереноса в рудничной вентиляционной сети, на основании математического моделирования обосновали применение местного кондиционирования воздуха для улучшения микроклиматический условий. В результате комплексного анализа данных, полученных аэрологами из Горного института и медиками из Федерального центра управления рисками, разработан уникальный для России и стран СНГ подход к обеспечению безопасных условий труда горнорабочих в условиях нагревающего микроклимата.

Аналогичное исследование проводилось для нефтяных шахт ООО «Лукойл-Коми», где вследствие специфики применяемого термошахтного метода добычи нефти наблюдаются очень высокие значения температуры и влажности воздуха [6].

\section{Расчет и мониторинг искусственного замораживания пород}

При строительстве подземных сооружений в сложных гидрогеологических условиях необходимо применять специальные способы. Наиболее распространенным специальным способом строительства шахтных стволов является способ искусственного замораживания пород $[7,8]$, суть которого заключается в формировании вокруг строящегося шахтного ствола ледопородного ограждения (ЛПО). Для разработки адекватных методов расчета и мониторинга состояния ЛПО возникает необходимость анализа множества взаимосвязанных физических процессов: теплопроводности, фазовых превращений поровой влаги, фильтрации подземных вод, изменения напряженнодеформированного состояния замораживаемых пород, их пучения и пр. [9, 10]. Взаимосвязь различных физических процессов условно изображена на рис. 1 - в данном случае все физические процессы разделены на 4 группы и объединены в соответствующие субмодели, формирующие единую связанную модель термогидромеханических процессов в ЛПО. Связь между субмоделями осуществляется посредством некоторых безразмерных комплексов $\Pi_{i}$, подробно исследованных нашей командой аэрологов и механиков.

Для решения этой сложной физической задачи, требующей анализа множества связанных физических процессов, были привлечены специалисты из Института ме- 
ханики сплошных сред УрО РАН, обладающие глубокими знаниями закономерностей деформирования и разрушения различных сред в их взаимосвязи с тепломассопереносом.

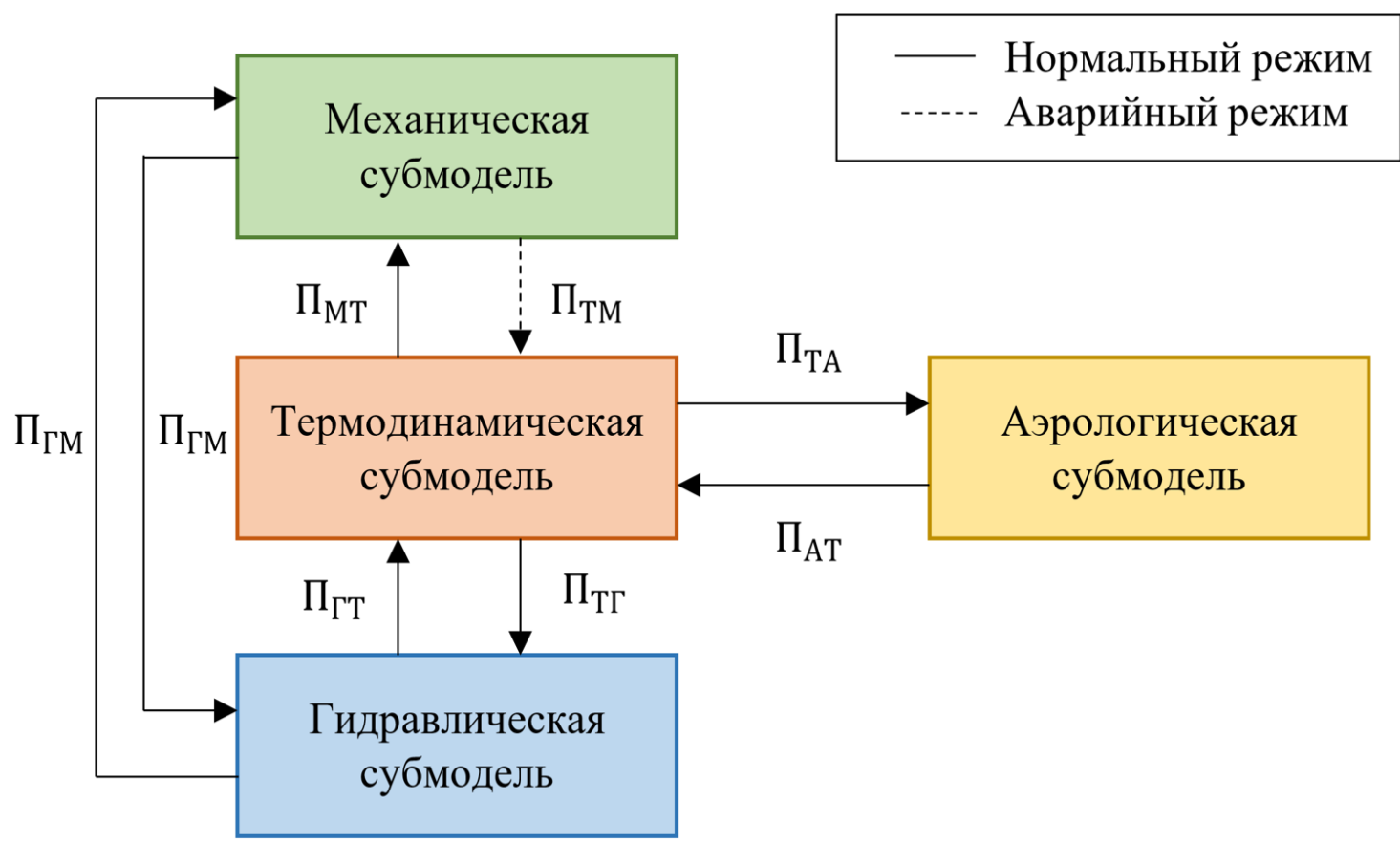

Рис. 2. Взаимосвязь различных субмоделей в связанной модели термогидромеханических процессов ЛПО

Параметризация математических моделей, разрабатываемых механиками, осуществлялась с использованием данных о теплофизических и физикомеханических свойствах пород, полученных нами совместно с сотрудниками Института природопользования НАН Республики Беларусь, а также данных натурных измерении температуры в контрольно-термических скважинах, собранных и обработанных сотрудниками нашего отдела. В результате комплексных теоретико-экспериментальных исследований нашим коллективом получены новые знания о закономерностях протекания физических процессов при формировании, поддержании и ликвидации ЛПО. Получены новые, более совершенные инженерные методы расчета ЛПО - как статического, так и теплотехнического. Полученные результаты легли в основу нормативного документа [11], который сегодня определяет организацию искусственного замораживания пород на строящихся рудниках АО «Беларуськалий».

\section{Деформационный мониторинг надшахтного здания скипового ствола}

Еще одной интересной задачей, связанной с ЛПО, является исследование деформирования фундамента и металлической конструкции надшахтного здания скипового ствола с копром в условиях постепенного оттаивания ЛПО вокруг построенного ствола, сопровождающегося усадкой тающего грунта. Данное исследование проводилось для одного из строящихся калийных рудников в Республике Беларусь и было вызвано тем, что по данным теоретического анализа и экспериментального мониторинга ЛПО вокруг ствола будет оттаивать очень медленно (несколько лет) даже при искусственном воздействии на грунт с помощью теплоносителя. Наличие замороженных пород под строящемся надшахтным зданием 
опасны как минимум по двум причинам: сложности с установкой свай фундамента в таких породах и усадка грунта при последующем их оттаивании. При этом из экономических соображений требовалось в сравнительно более короткие сроки построить и ввести в эксплуатацию надшахтное здание.

Для обоснования возможности строительства надшахтного здания скипового ствола потребовалось провести комплексные исследования тепловых и деформационных процессов в системе «надшахтное здание - фундамент - сваи - грунт». Научный коллектив отдела аэрологии и теплофизики совместно с лабораторией интеллектуального мониторинга Института механики сплошных сред УрО РАН успешно справились с поставленной задачей. Коллективом проведено исследование, на первом этапе которого выполнено математическое моделирование системы с целью определения наиболее «слабых» с точки зрения несущей способности элементов системы (см. рис. 3). На втором этапе по данным моделирования была развернута автоматизированная система деформационного мониторинга перемещений (АСДМП), осуществляющая непрерывную регистрацию усадок грунта, измерение осевых деформаций, температуры, углов наклона исследуемых элементов системы, регистрацию нестационарных вибрационных процессов в конструкции (см. рис. 4). Данная система является уникальной разработкой лаборатории интеллектуального мониторинга, не раз применявшейся ранее при анализе деформирования жилых зданий. А благодаря описываемому совместному проекту данная система впервые была успешно применена для здания горнодобывающего предприятия.

Анализ результатов работы АСМДП за 2020 г. позволил установить, что основным фактором, определяющим деформационные процессы в элементах надшахтной конструкции, является взаимодействие бетонного оголовка скипового ствола с опорными колоннами конструкции. Наибольшее влияние на эти процессы оказывают сезонные изменения температуры. По полученным данным с АСМДП и численного моделирования было установлено, что надшахтная конструкция в текущем состоянии справляется с имеющимися нагрузками и нет необходимости в её дополнительном укреплении.
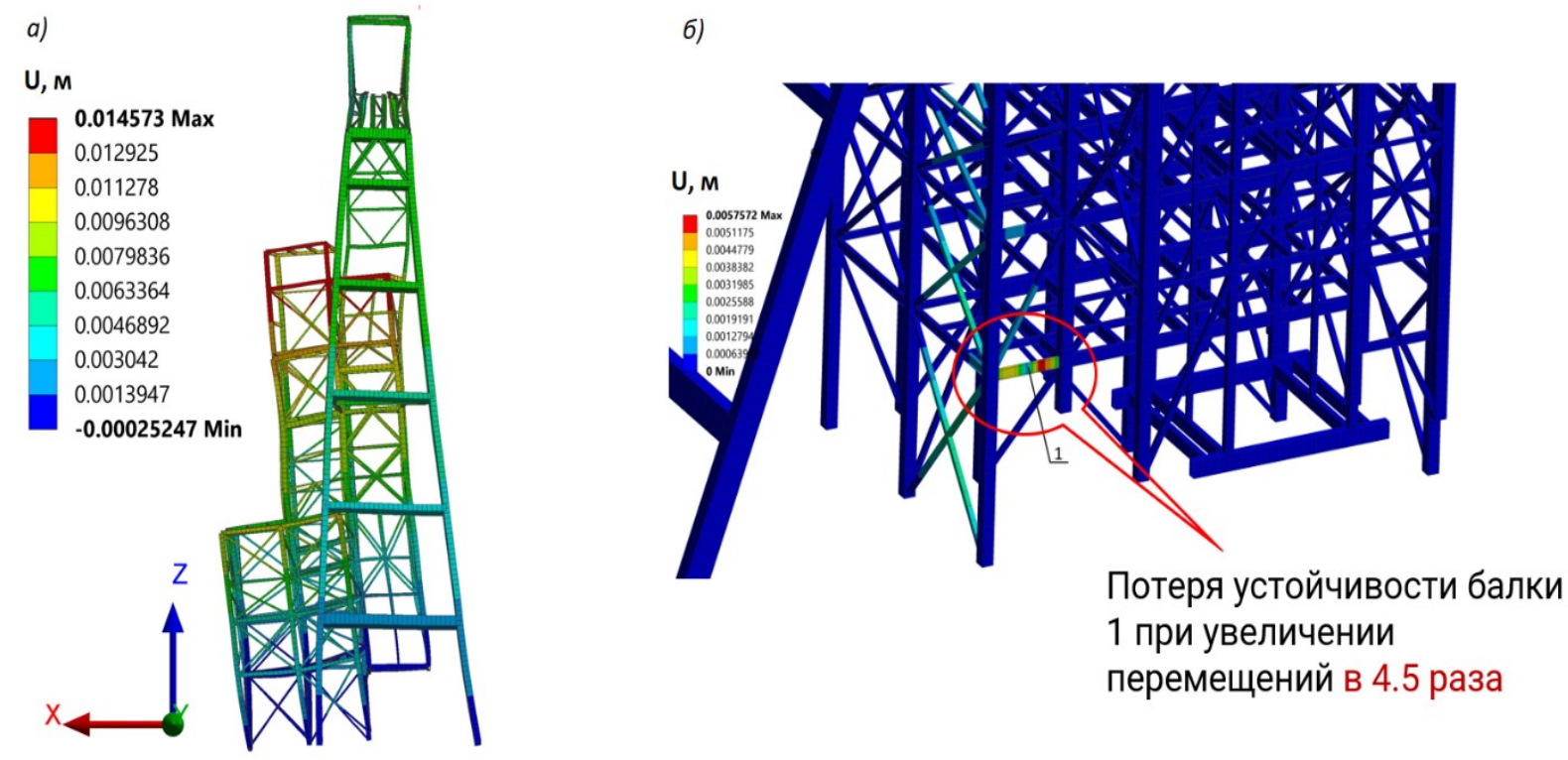

Рис. 3. Горизонтальные перемещения конструкции копра (а) и амплитуда вектора перемещений при первой форме потери устойчивости (б) 


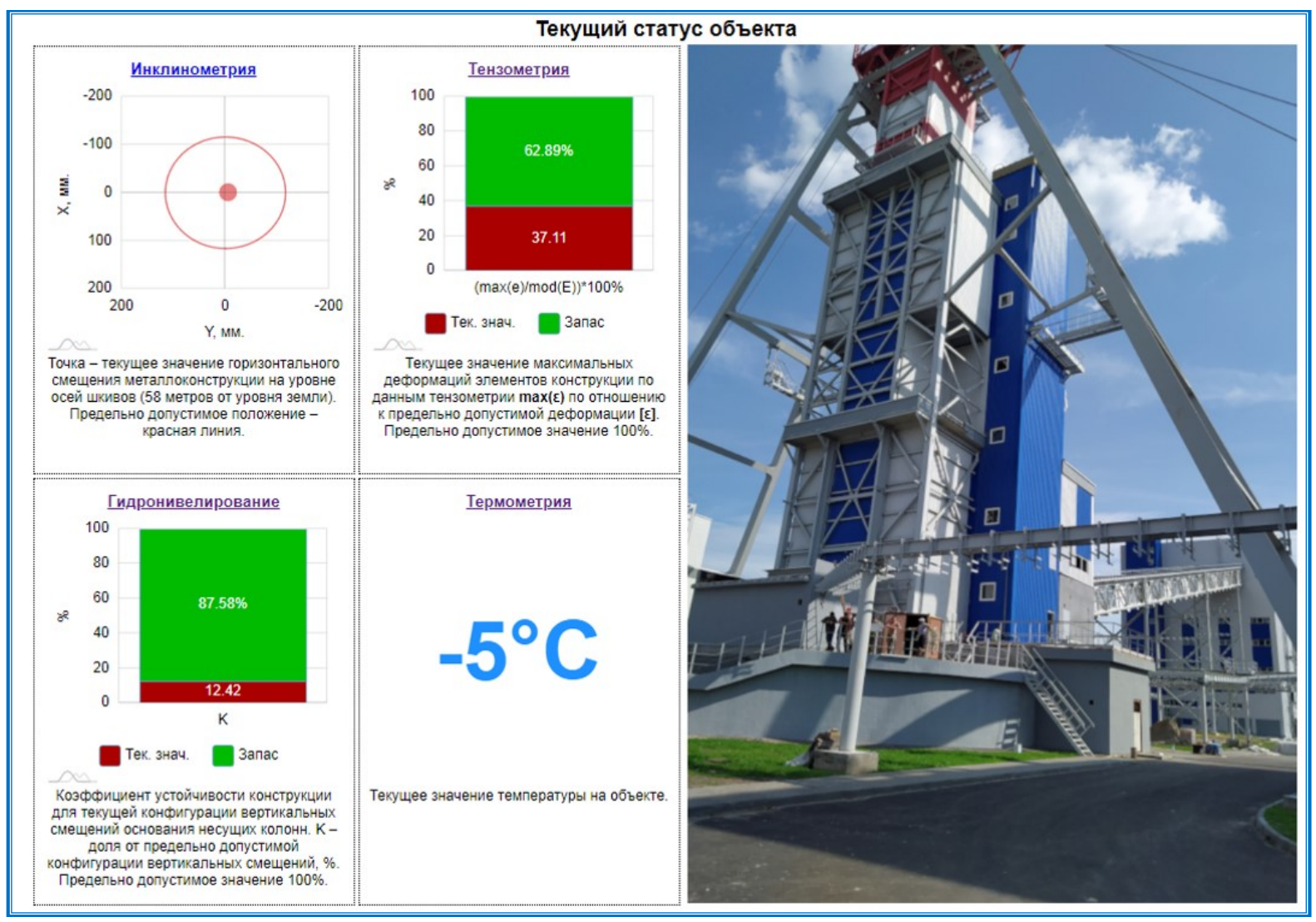

Рис. 4. Веб-интерфейс автоматизированной системы деформационного мониторинга конструкции

\section{Заключение}

Хочется отметить, что нами был получен положительный опыт выполнения междисциплинарных исследований - как в плане прикладных аспектов, связанных с внедрением в практику, так и для фундаментальной науки, повышения публикационной результативности. Это подтверждается множеством заключенных и успешно выполненных хозяйственных договоров с предприятиями, статей, опубликованных в ведущих иностранных журналах 1-го и 2-го квартилей, поддержанных научных грантов Российского научного фонда, Российского фонда фундаментальных исследований, фонда Совета при президенте Российской Федерации.

В статье описаны лишь некоторые междисциплинарные проекты, в то время как в эти годы проводились и другие работы: совместно с учеными из ИЭГМ УрО РАН и ИТХ УрО РАН проводились исследования окисления и самонагревания сульфидных руд в медно-никелевых рудниках [12], совместно с сотрудниками Пермского НИИСХ исследованы способы повышения сохранности картофеля при хранении в атмосфере калийных рудников [13], совместно с механиками из ИМСС УрО РАН разработана уникальная модель термогидромеханических процессов в пластах при добыче высоковязких нефтей [14]. Также было заключено соглашение о научном сотрудничестве с Высшей школой технических наук им. Георга Агриколы [15].

\section{БИБЛИОГРАФИЧЕСКИЙ СПИСОК}

1. Фридман В. Россия-Великобритания научное сотрудничество на мировом уровне // В мире науки. 2014. - №. 1. - С. 36-41.

2. Файнбург Г.З., Исаевич А.Г. Анализ микроциркуляционных потоков между микрозонами в забое тупиковых комбайновых выработок калийных рудников при различных способах проветривания // 
Горный информационно-аналитический бюллетень (научно-технический журнал). - 2020. - № 3. - С. 58-73. - DOI: 10.25018/0236-1493-2020-3-0-58-73.

3. Семин М.А., Исаевич А.Г., Жихарев С.Я. Исследование оседания пыли калийной соли в горной выработке // Физико-технические проблемы разработки полезных ископаемых. - 2021. - № 2. - С. 178191. - DOI: 10.15372/FTPRPI20210218.

4. Зайцев А.В., Бородавкин Д.А., Поляков И.В. Обеспечение безопасных условий труда по фактору микроклимата для условий глубокого калийного рудника // Горное эхо. - 2020. - № 1 (78). - С. 72 79. - DOI: 10.7242/echo.2020.1.16.

5. Зайцев А.В., Семин М.А., Клюкин Ю.А. Исследование критериев нормирования микроклиматических условий в горных выработках // Горный информационно-аналитический бюллетень (научнотехнический журнал). - 2015. - № 12. - С. 151-156.

6. Устинова О.Ю., Костарев В.Г., Алексеев В.Б., Власова Е.М., Носов А.Е., Зайцев А.В., Левин Л.Ю. Влияние условий труда на функциональное состояние организма работников, занятых на добыче нефти термошахтным способом // Гигиена и санитария. - 2020. - Т. 99, № 11. - С. 1222-1229.

7. Левин Л.Ю., Семин М.А., Зайцев А.В. Контроль и прогноз формирования ледопородного ограждения с использованием оптоволоконных технологий // Стратегия и процессы освоения георесурсов: сб. науч. тр. Вып. 14 / ГИ УрО РАН. - Пермь, 2016. - С. 236-238.

8. Левин Л.Ю., Семин М.А., Зайцев А.В. Калибровка теплофизических свойств породного массива при моделировании формирования ледопородного ограждения строящихся шахтных стволов // Физикотехнические проблемы разработки полезных ископаемых. - 2019. - № 1. - С. 172-184. - DOI: $\underline{\text { 10.15372/FTPRPI20190119. }}$.

9. Левин Л.Ю., Зайцев А.В., Семин М.А. Контроль теплового режима породного массива на основе применения оптоволоконных технологий мониторинга температур в скважинах // Горное эхо. -2016. - № 1 (62). - C. 35-37.

10. Kostina A., Zhelnin M., Plekhov O., Panteleev I., Levin L., Semin M. Applicability of Vyalov's equations to ice wall strength estimation // Frattura ed integrita strutturale. - 2020. - V. 14, № 53. - P. 394-405. - DOI: 10.3221/IGF-ESIS.53.30.

11. Инструкция по расчету параметров, контролю и управлению искусственным замораживанием горных пород при строительстве шахтных стволов на калийных рудниках ОАО «Беларуськалий. Пермь; Солигорск, 2019. - 65 с.

12. Левин Л.Ю., Кормщиков Д.С., Гришин Е.Л. Исследование процессов изменения рудничной атмосферы для определения причин произошедшего группового несчастного случая на одном из рудников РФ // Горное эхо. - 2020. - № 3 (80). - C. 115-119. - DOI: 10.7242/echo.2020.3.22.

13. Шалимов А.В., Левин Л.Ю., Исаевич А.Г., Семин М.А. Исследование влияния калийного аэрозоля на влажность и ионизацию воздуха при проветривании хранилищ сельскохозяйственной продукции // Горное эхо. - 2018. - № 3 (72). - С. 42-49.

14. Костина А.А., Желнин М.С., Плехов О.А., Клюкин Ю.А. Связанная термогидромеханическая модель фильтрации нефти в пористой среде // XXI Зимняя школа по механике сплошных сред: тез. докл. / ИМСС УрО РАН. - Пермь, 2019. - С. 159.

15. Левин Л.Ю., Зайцев А.В., Д.С. Кормщиков, Семин М.А. Поездка в высшую школу технических наук им. Георга Агриколы // Горное эхо. - 2018. - № 3 (72). - С. 55-57.

\title{
ОСОБЕННОСТИ ТЕПЛОФИЗИЧЕСКОГО РАСЧЕТА ЛЕДОПОРОДНЫХ ОГРАЖДЕНИЙ ШАХТНЫХ СТВОЛОВ РУДНИКА ГРЕМЯЧИНСКОГО ГОК
}

\author{
А.А. Оглоблина ${ }^{1}$, А.В. Пугин ${ }^{1}$, И.В. Поляков ${ }^{2}$ \\ ${ }^{I}$ Горный институт УрО РАН, г. Пермь \\ ${ }^{2}$ ООО «ЕвроХим-ВолгаКалий»
}

\begin{abstract}
Аннотация: В статье описаны особенности параметризации теплофизических моделей для шахтных стволов калийного рудника Гремячинского ГОКа. Описаны параметры, подвергающиеся калибровке, и алгоритм выполнения калибровки теплофизической модели.

Ключевые слова: Гремячинский ГОК, искусственное замораживание пород, ледопородное ограждение, теплофизическая модель, калибровка.
\end{abstract}

